\title{
Imagens, Conceitos e Cultura Política: A pintura sobre a Independência da Colômbia na primeira metade do século XIX
}

\author{
Yobenj Aucardo Chicangana-Bayona ${ }^{1}$
}

O artigo estuda as representações visuais sobre a Independência da Colômbia na primeira metade do século XIX, especialmente a substituição dos símbolos imperiais espanhóis por novos símbolos republicanos, salientando obras como as alegorias da liberdade e da pátria e os retratos dos heróis como modelos de cidadão. A análise dessas fontes permite, primeiro, perceber as dificuldades de representar novos conceitos visualmente e, segundo, que os debates sobre a cultura e as linguagens políticas podem ser enriquecidos com o estudo das fontes pictóricas.

Palavras-chave: Iconografia - Independência - Colômbia Século XIX - Símbolos Republicanos - Pátria - Liberdade

\section{Images, Concepts and Political Culture: Paintings relating to Colombian} Independence in the First Half of the Nineteenth Century

The article examines visual representations of Columbian Independence in the first half of the 19th century, especially the replacement of Spanish imperial symbols by new republican ones. highlighting works such as allegories of liberty and fatherland, and portraits of heroes as models for the citizen. The the analysis of these sources shows, firstly the difficulties of representing new concepts in a visual medium and, secondly,

\footnotetext{
${ }^{1}$ Professor titular do Departamento de História da Facultad de Ciencias Humanas y Económicas da Universidad Nacional de Colombia, sede Medellín. Doutor e mestre em história pela Universidade Federal Fluminense.E-mail: yobenj@gmail.com, yachican@unal.edu.co As imagens que acompanham este texto podem ser vistas em cores em sua versão eletrônica.
} 
that the study of pictorial sources can enrich the debates about political culture and languages.

Keywords: Iconography - Independence - Nineteenth-Century Colombia - Republican Symbols - Fatherland - Liberty

Images, concepts et culture politique: La peinture de l'indépendence colombienne dans la première moitié du XIXe siècle

Cet article propose d'examiner la représentation visuelle de l'Indépendance de la Colombie: les symboles espagnols de l'Empire sont remplacés par de nouveaux symboles républicains. Plus particulièrement, ce sont les allégories de la liberté et de la patrie, comme les portraits du héros en tant que modèle du citoyen qui en font l'objet. L'analyse de ces sources permet de percevoir d'une part les difficultés que se présentaient à l'époque pour rendre de manière visuelle ces nouveaux concepts; d'autre part, elle veut suggérer combien l'étude de la peinture peut enrichir les débats sur les idées de culture politique et de langages politiques.

Mots-clés: Iconographie - Indépendence - Colombie au XIXe siècle - Symboles républicains - Patrie - Liberté

A transição da atual Colômbia de colônia a república, com a autonomia inicial e depois com as guerras de independência, gerou mudanças e a passagem de uma ordem imperial para uma republicana. Esse processo pode ser rastreado na transformação da linguagem política com a qual surgem novos conceitos, enquanto outros terminam adaptados e ressignificados: liberdade, pátria, igualdade, constituição, república, entre muitos outros. Mas esses debates no âmbito da cultura e da linguagem política não se limitam aos discursos e à escrita, podendo ser também encontrados e percebidos por meio das representações pictóricas.

Este artigo ocupa-se do problema de representar conceitos por meio de imagens. Nesse sentido, trata-se a mudança e a substituição dos símbolos imperiais hispânicos pelos republicanos, concretamente, de conceitos como liberdade e pátria a partir das pinturas alegóricas; a substituição da imagem do rei pela de Bolívar como Pai da Pátria. Os novos modelos do cidadão encarnados nas galerias sobre os heróis e a representação feminina como sujeito político são alguns dos aspectos analisados no presente texto. 


\section{Imagens da liberdade e da pátria}

Por meio das alegorias, é possível rastrear o processo de autonomia, insurgência e ruptura que finalmente exige a substituição dos símbolos imperiais e as efígies de Fernando VII pela índia crioula de aljava, cocar e saia de penas. Iniciados o processo de emancipação e a conformação das primeiras repúblicas, a alegoria da América foi ressignificada tanto na sua representação iconográfica quanto no seu conceito. Os moradores das colônias espanholas reconheceram-se inicialmente como americanos, por isso continuaram usando a figura da América como tinha sido constituída na Europa, e agora, no contexto republicano, a alegoria é retomada como parte da diferença. Esse processo transformaria a alegoria da América primeiro em símbolo de liberdade e, mais tarde, associado com as identidades territoriais das novas repúblicas, em símbolo da Pátria.

\section{As alegorias da quarta parte}

A representação da América como uma mulher é uma temática europeia muito popular na Renascença, sendo associada às quatro partes ou quatro cantos do mundo. Essas alegorias são personificações femininas com atributos físicos, roupas, objetos alusivos que representam os continentes conhecidos até então: Europa, Ásia, África e América.

A alegoria é a figura da retórica que diz uma coisa para significar outra. Essa tradição data da época clássica e tem muita aceitação durante os séculos XVI e XVII. Cesare Ripa, seguidor de Ficino, publicou sua obra Iconologia em 1593, e anos depois, em 1603, a obra apareceria acompanhada por xilogravuras. Nesse livro, são descritas as quatro partes ou quatro cantos do mundo. Essa divisão e ordenação do mundo será bastante comum nos livros de costumes. Ripa refere-se à quarta parte, a América, assim:

[...] Mujer desnuda y de color oscuro, mezclado de amarillo. Será fiera de rostro, y ha de llevar un velo jaspeado de diversos colores que le cae de los hombros cruzándole todo el cuerpo, hasta cubrirle enteramente las vergüenzas. Sus cabellos han de aparecer revueltos y esparcidos, poniéndosele alrededor de todo su cuerpo un bello y artificioso ornamento, todo él hecho de plumas de muy diversos colores. Con la izquierda ha de sostener un arco, y una flecha con la diestra, poniéndosele al costado una bolsa o carcaj bien provista de flechas, así como bajo sus pies una cabeza humana traspasada por alguna de las saetas que digo. En tierra y al otro lado se pintará algún lagarto o un 
Figura 1. Marten de Vos e Adriaen Collaert. As alegorias dos continentes. Amsterdã. 1600. Superior: América e África. Inferior: Europa e Ásia.
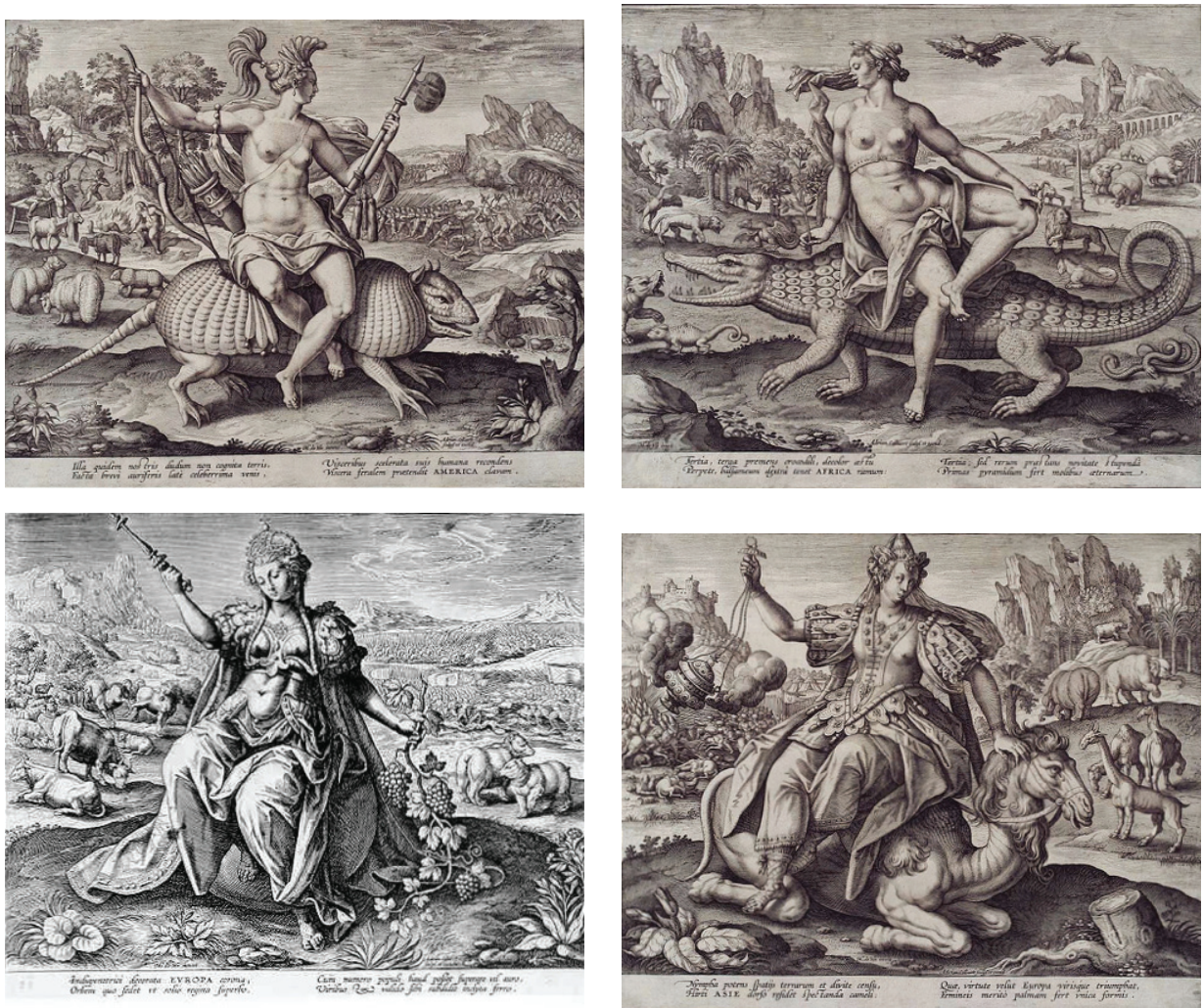

caimán de desmesurado tamaño... El cráneo humano que aplasta con los pies muestra bien a las claras cómo aquellas gentes, dadas a la barbarie, acostumbran generalmente a alimentarse de carne humana, comiéndose a aquellos hombres que han vencido en la guerra, así como a los esclavos que compran y otras diversas víctimas, según las ocasiones. En cuanto al Lagarto o Caimán es un animal muy notable y abundante en esta parte del Mundo, siendo tan grandes y fieros que devoran a los restantes animales y aún a los hombres en ciertas ocasiones [...].2

As representações da América como uma mulher são frequentes desde 1575 e continuarão se repetindo nos séculos seguintes. Os relatos iniciais de Cristóvão Colombo e Américo Vespucci sobre os habitantes do Novo Mundo e suas práti-

\footnotetext{
${ }^{2}$ Cesare Ripa, Iconología (1613), Madri, Ediciones Akal, 2002, 2 t., p. 108-109.
} 
cas antropofágicas serão uma das características distintivas do continente americano, pelo menos até o final do século XVII. Por isso, a representação da América não só é associada a uma mulher selvagem, seminua e vestida com penas, arco e aljava, mas também associada com a prática do canibalismo, as riquezas de suas minas, a fertilidade da terra e a natureza exótica infestada de animais gigantescos e estranhos.

$\mathrm{Na}$ origem, a mulher que representava a América na iconografia aparecia montando um tatu, vestida de penas e portando arco, aljava, setas e machado, nas gravuras de Marten de Vos e Adriaen Collaert, de 1600 (Figura 1). A alegoria da África estava representada sobre um grande caimão. Como tornou-se o caimão sela da alegoria da América? Acredito que a razão seja que, nos anos seguintes, as iconografias das duas alegorias se difundiram amplamente, misturando-se e trocando alguns dos seus atributos. Finalmente, essas alegorias procuravam representar uma alteridade diferente ao europeu, inferior, exótica e primitiva, como eram consideradas a América e a África naquele momento. Nessas trocas terminou por triunfar a imagem da América que monta o grande caimão.

Com a expansão da fronteira de exploração europeia e a consolidação da colonização, durante o século XVIII, os relatos de viagem não associam mais o Novo Mundo ao canibalismo, mas, sim, às ilhas e moradores do Pacífico Sul, à nova fronteira e à zona menos explorada. ${ }^{3}$ Essa mudança na percepção do outro leva a transformar as representações das alegorias da América, que não fazem mais alusão ao canibalismo ou à guerra, dando um maior destaque à fertilidade e à riqueza das terras. Por isso aparece o corno da abundância cheio de frutas e, em outras ocasiões, de ouro e riquezas. Por outro lado, a América continua aparecendo como uma mulher seminua vestida de penas, coroa e saias, ao lado dos emblemas de uma fauna exótica americana, como o caimão gigante e o papagaio.

Especialmente durante o século XVIII, é importante salientar uma situação particular relacionada com as alegorias: essas imagens já não são realizadas somente na Europa, mas também nos diferentes vice-reinos, com motivos tais como festas e comemorações. Então, o sentido da alegoria muda, já não é só uma visão europeia pejorativa do continente exótico, selvagem e degradado, mas,

${ }^{3}$ Yobenj Aucardo Chicangana-Bayona, "El nacimiento del caníbal: un debate conceptual”, Revista Historia Critica, Bogotá, n. 36, jul./dez. 2008, p. 150-173. 
paralelamente, também um mecanismo de autorreferência, identificação e, em certos casos, de identidade prematura das colônias.

Com o contexto das guerras de independência, a alegoria da América se transformará simbolizando a liberdade e a república, sendo representada como uma mulher que acaba de ser liberada das correntes da opressão, embora ainda continuem aparecendo as cornucópias e artefatos indígenas.

\section{As alegorias neogranadinas}

A primeira reflexão que surge tem a ver com uma temática europeia, pejorativa, associada ao selvagem e ao exótico, como são as representações da América como a "quarta parte" ou "quarto canto". Elas terminam sendo apropriadas e reinterpretadas pelos crioulos americanos, que transformam a alegoria em um símbolo de identidade, de pertença e de pátria.

Os episódios que acontecem na metrópole, seus reinos e colônias alteram as formas de percepção e de representação das alegorias da América, que ganham novas funções não só para se referir às partes distantes do império, mas também como laço ou vínculo entre a metrópole e as colônias ao celebrar e comemorar juramentos ou honras funerárias.

A Biblioteca Nacional de Madri conserva um manuscrito de 146 fólios que descreve as honras e exéquias levadas a cabo em Santafé em homenagem ao rei Dom Luís Fernando. Esse manuscrito está acompanhado de aquarelas. A primeira página é um frontispício presidido pelas alegorias da América e de Santafé. A imagem da América está à esquerda, de túnica, coroada com um cocar de penas, armada de setas, arco e um papagaio na mão direita. A outra mulher, também de túnica, à direita, representa Santafé, leva uma romã na mão esquerda e a seus pés uma águia. Nos cantos inferiores, dois leões custodiam a entrada, símbolos da monarquia hispânica. A inscrição diz ao Rei Nosso Sr. Dn. Philipo V. em seu Real e Supremo Conselho das Índias. O documento datado o 12 de junho de $1726 .^{4}$

\footnotetext{
${ }^{4}$ Marta Fajardo de Rueda, "Arte y poder. Las honras fúnebres del rey Luis Fernando, el primer Borbón madrileño, en Santa Fé de Bogotá en el año de 1725”. In: Yobenj Aucardo Chicangana-Bayona (compilador), Caminos cruzados: historia, cultura e imágenes, Medellín, Universidad Nacional de Colombia, 2010, p. 89-115.
} 
O frontispício mostra a América e Santafé unidas pela dor da infausta notícia da morte do rei. Esse documento busca informar e destacar ao novo rei Felipe $\mathrm{V}$ as demonstrações de luto acontecidas na Real Audiência e na cidade de Santafé pela morte do rei Luís Fernando.

Outro caso semelhante aconteceu em Santafé para o juramento de Fernando VII como rei no dia 11 de setembro de 1808 , em que foi apresentado um emblema com duas mulheres, as alegorias da Europa e da América:

[...] vino al Nuevo Reino de Granada el delegado español Juan José de Sanllorente. En la celebración, según José Acevedo y Gómez, encargado del Cabildo de Santafé, se exhibe un emblema en el que aparecen dos matronas de bella actitud, sentadas en dos continentes divididos por el mar. La una representa a España, la otra la América, con sus respectivos atributos cada una [...]. ${ }^{5}$

Os críticos anos 1808-1810, iniciados com a abdicação e a prisão de Fernando VII e a posterior ocupação francesa da Espanha, geraram reações que levaram os crioulos das colônias a se questionarem sobre a ordem estabelecida. $\mathrm{O}$ vazio de poder gerou entre os crioulos reflexões fundamentais sobre quem os governava e a quem deviam render lealdade na ausência do rei. Em um primeiro momento, a reação foi reafirmar a lealdade ao rei cativo e o pertencimento das colônias à nação espanhola, sem que isso impedisse os crioulos de exigir uma maior participação na ordem imperial. Por outro lado, os espanhóis peninsulares viram essas propostas políticas como ameaças a seu poder nos territórios de ultramar. ${ }^{6}$

Nessa conjuntura surge a necessidade de reafirmar a lealdade, e um dos meios para esse propósito foram as imagens. As corporações respaldadas por grêmios nos vice-reinos como Nova Granada ou Peru patrocinariam alegorias que representam a Espanha e a América, esta última tendo sido substituída pelos vicereinos como identidades territoriais, sempre salientando o apoio ao rei cativo e a irmandade entre os povos.

\footnotetext{
${ }^{5}$ Juan Ricardo Rey Márquez, "Los indígenas europeos: la india de la libertad”, Colección de Numismática. Cuadernos de Curaduría, n. 2, Bogotá, Museo Nacional de Colombia, 2005, p. 7. Disponível em: <http://redmuseo.javeriana.edu.co/inbox/files/docs/calegoria.pdf>, acesso em 3.3.2009.

${ }^{6}$ Esther Acevedo, "Entre la tradición alegórica y la narrativa factual". In: Los pinceles de la historia. De la patria criolla a la Nación Mexicana 1750-1786, México, Consejo Nacional para la Cultura y las Artes, 2001, p. 116-117.
} 
Entre 1808 e 1810, foram publicados folhetos de todo tipo que mostram os sentimentos de incerteza relacionados com os fatos da metrópole. Realizaram-se alegorias para mostrar o apoio à monarquia espanhola sob o domínio francês. As gravuras antinapoleônicas reforçavam as alegorias da união da Espanha, como uma mulher de roupagens clássicas romanas, e da Nova Espanha, como uma mulher vestida de penas que unem esforços respaldados pela religião para socorrer o amado monarca Fernando VII ou fazer empréstimos aos espanhóis peninsulares (Figura 2).

Figura 2. A Antiga e a Nova Espanha juram em mãos da religião vingar Fernando VII, 1809. Cat. 228.

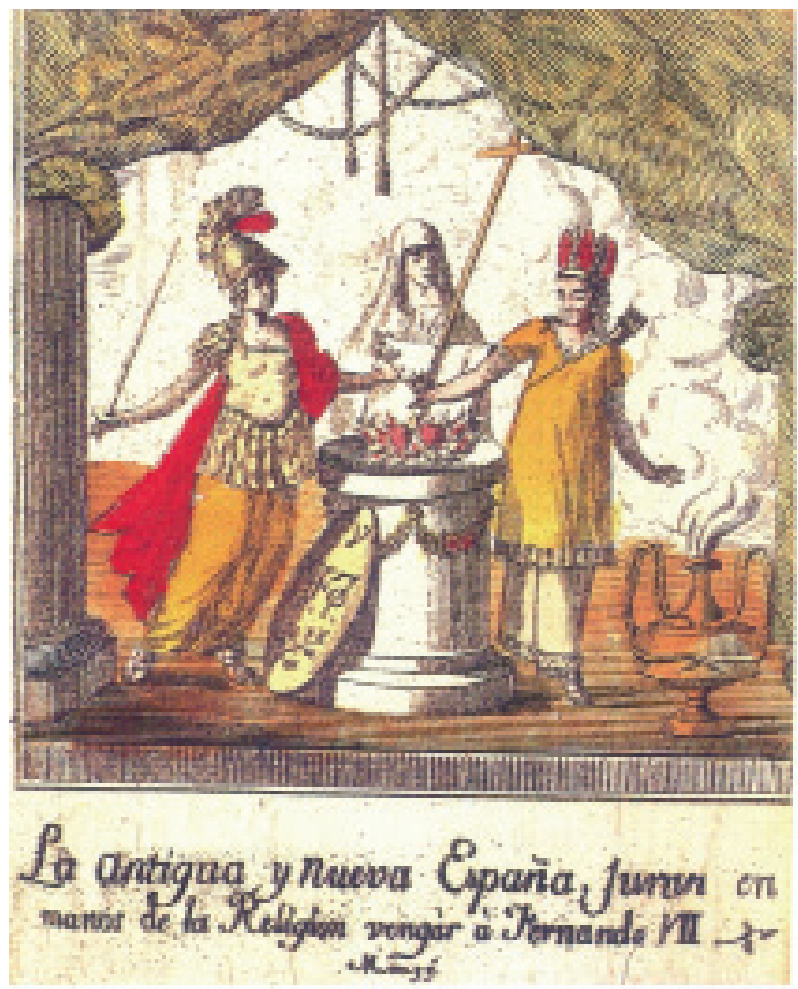

Com o processo de emancipação da Nova Granada, a alegoria da América transformou-se, a partir de 1813, em alegoria da liberdade, representada por uma mulher de pele branca, cabelos pretos e longos, coroada por um cocar, vestida de saia de penas, com aljava e setas. A alegoria da índia da liberdade viria a presidir 
as cerimônias civis em Santafé em substituição aos retratos do rei Fernando VII. O diário de José María Caballero, do dia 5 de julho de 1813, comenta sobre uma dessas cerimônias:

[...] A 5 declaró el colegio electoral el total desconocimiento y separación absoluta de la nación española y de su rey Fernando VII, y de toda otra potestad y dominación extranjera no reconociendo más el gobierno que el de Cundinamarca, libre e independiente. Desde esta hora comenzaron a gritar los verdaderos patriotas la independencia, con alegres repiques de campanas y voladores. A la noche sacaron el retrato de la Libertad en paseo, con muchos vivas y voladores, músicas y aclamaciones. Dio una gran vuelta mandando se iluminase por donde quiera que pasó. Los realistas se enfadaron y tuvieron a mal, por supuesto, pues perdían sus esperanzas favoritas para sus pretensiones $[\ldots]]^{7}$

Desde os primeiros anos da república, os Estados soberanos, como Cartagena, ao declararem sua independência absoluta, substituíram os símbolos imperiais espanhóis e adotaram a representação da índia liberada, como distintivo, emblema de liberdade e independência, como nos casos do escudo da constituição do Estado de Cartagena de 1812 e nas efígies das moedas cunhadas.

Na primeira página da Constituição do Estado de Cartagena de Índias, sancionada em 14 de junho do ano de 1812, Segundo da sua independência encontra-se um escudo circular em que é representada uma índia ricamente adornada, com cocar e saia de penas, com uma aljava e setas nas suas costas e encostada contra uma palmeira. Na mão direita segura uma granada, da qual se alimenta uma ave. Na sua mão esquerda segura algumas correntes quebradas. No fundo, percebemse dois morros com edificações, o da direita é o "cerro de la Popa", um dos morros tutelares da cidade de Cartagena.

As moedas cunhadas pelo Estado de Cartagena de Índias em 1812 repetem a índia com seus atributos segurando a romã e as correntes quebradas. A paisagem de fundo muda: os morros são trocados por palmeiras. As imagens das índias ou das "chinas", 8 como foram chamadas na época, acabaram sendo cunhadas nas diferentes províncias e Estados, substituindo a efígie do rei Fernando VII:

\footnotetext{
${ }^{7}$ José María Caballero, Diario de la patria boba, Bogotá, Editorial Incunables, 1986, p. 137.

8 "Chinas" era o nome dado às faxineiras de origem indígena.
} 
[...] En la presidencia de Nariño se acuñó una moneda de plata de baja ley $(0,583)$ en la que se remplazó la efigie de Fernando VII, como consta en la Gazeta Ministerial de Cundinamarca (19 de agosto de 1813): "la moneda de la nación tiene por un lado el busto de la libertad y esta inscripción libertad americana; por el otro una granada y esta inscripción; Nueva Granada. Cundinamarca”. Así que la libertad es el perfil de una indígena, con una corona de plumas en la cabeza. Posteriormente se hicieron otras emisiones, aprobadas por el Libertador presidente y el vicepresidente Santander, con los siguientes cambios: entre 1819 y 1820 con la leyenda "Nueva Granada" en el reverso y entre 1821 y 1828 con las leyendas "República de Colombia" en anverso y "Cundinamarca" en el reverso [...]. ${ }^{9}$

Nas moedas, gravuras e documentos circularam simultaneamente efígies da índia e da mulher com roupas clássicas e barrete frígio como alegorias da liberdade. Até finais da segunda década do século XIX, será frequente achar as efígies da índia associadas à liberdade e à pátria.

A necessidade da nova república de comemorar a independência e celebrar a liberdade estimulou e convidou os pintores neogranadinos a se aventurarem a representar temáticas como as alegorias. Uma pintura anônima, datada de 1819 e atualmente no Museu da Independência de Bogotá, representa uma índia ricamente adornada com colares e brincos, sentada, com uma palmeira ao fundo e aos seus pés um caimão. Chamam a atenção nessa versão dois aspectos: o primeiro, que na pintura se inclui o texto "A Índia da Liberdade Ano de 1819", e o segundo, que a aborígine segura na sua mão esquerda uma lança e, sobre esta, um barrete frígio vermelho, emblema da liberdade, bastante comum desde a Revolução Francesa (Figura 3).

É importante esclarecer que a alegoria da liberdade tinha diversas possibilidades de representação. Uma dessas alternativas era uma mulher com roupas indígenas. A outra opção era uma mulher com toga grega e barrete frígio. Não acredito que uma ou outra forma de representação tivesse a ver com questões étnicas ou culturais entre a Europa e a América. Na verdade, a mulher representada sempre foi branca; era mais uma idealização de um passado indígena, e não se refere aos indígenas que moravam naquele momento na Nova Granada. Na pintura da índia da liberdade do Museu da Independência convergem as duas tradições.

\footnotetext{
${ }^{9}$ Rey Márquez, op. cit., p. 3.
} 
Figura 3. Anônimo. A Índia da Liberdade. Óleo sobre tela. $82,4 \times 62,4 \mathrm{~cm}$. Museo de la Independencia - Casa del Florero. Ministerio de Cultura de Colombia. Bogotá, 1819, Reg. 00018.

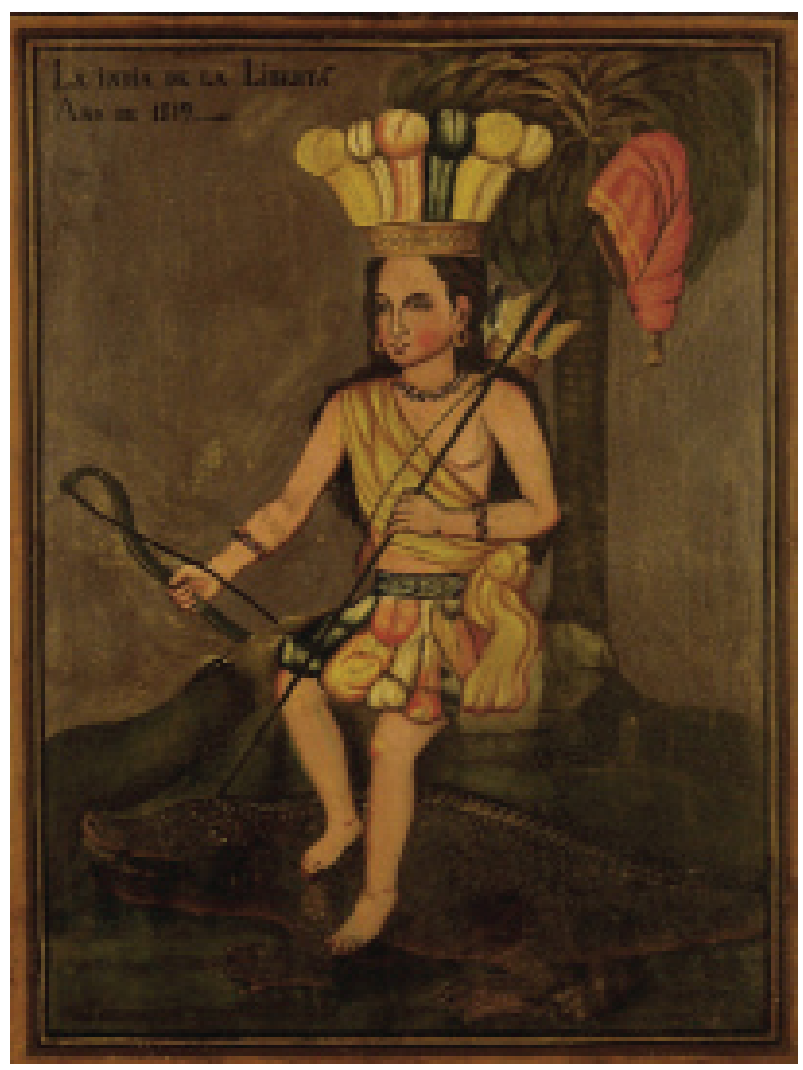

Só conheço o caso particular de um selo do almirantado da Venezuela que inclui as duas alegorias, simultaneamente, em uma mesma imagem. De um lado, uma paisagem do litoral com uma palmeira e uma indígena armada com aljava e setas, que segura com sua mão direita uma legenda que diz "Auxílio" e espera a liberdade. Outra mulher se aproxima em um barco, sustentando na sua mão direita uma lança com um barrete frígio içado na ponta e na sua mão esquerda uma âncora que prepara para o desembarque (Figura 4).

O selo do almirantado, bastante excepcional por incluir as duas alegorias, estabeleceria uma diferença entre a pátria representada pela índia e a liberdade 
representada pela mulher de roupas clássicas que vem no barco, que, além disso, seria uma metáfora da importância das forças navais para a causa republicana.

Figura 4. Selo do Almirantado da Venezuela.

Esquerda: Impressão em lacre. Direita: desenho do conteúdo.
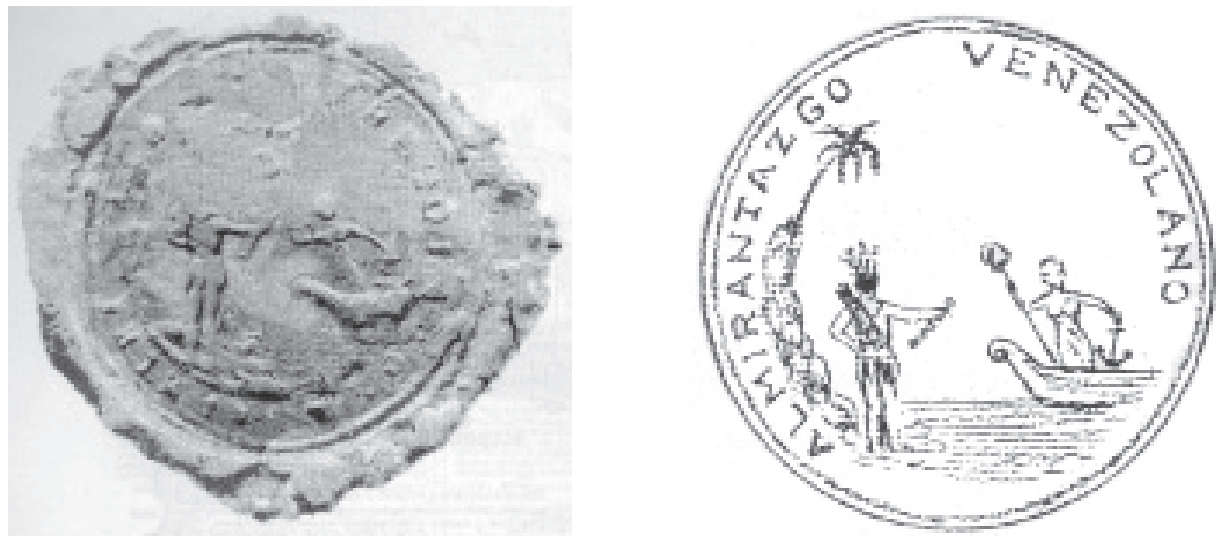

As imagens das alegorias deveriam ser pensadas como elementos retóricos previamente definidos, não como reflexos da sociedade ou narrações de episódios históricos. Essas representações formam parte de uma tradição alegórica e emblemática herdada da colônia, com um vocabulário conceitual de imagens que vem do século de XVI e que deve adaptar-se, no século XIX, às demandas representativas das novas nações e a cada contexto em particular: "Este modo de representación permite incorporar a personajes históricos reales con figuras codificadas en sus atributos que significan ideas abstractas, tales como virtudes, actividades humanas, formas de gobierno, etcétera." 10

A presença de índios como protagonistas das alegorias da liberdade e da pátria e outros símbolos republicanos, na Colômbia como em outros países, têm levado a pensar erradamente que a independência buscou a reivindicação social dos indígenas. O que fica claro é que a legitimidade do projeto nacional estava baseada no passado das civilizações pré-hispânicas. Aquela celebração do passado pré-colombiano pretendia deslegitimar a autoridade espanhola, por isso começam a ser usados nomes indígenas, como: Cundinamarca, Bogotá ou "o país dos antigos Zipas”, e símbolos como as índias, as setas, as lanças em escudos, selos

\footnotetext{
${ }^{10}$ Acevedo, op. cit., p. 115.
} 
e bandeiras. Mais do que representar os índios, os personagens das alegorias são crioulos brancos travestidos com ornamentos de penas que celebram a pátria.

Algo semelhante ao que acontecia nos tablados e nas celebrações pátrias da liberdade onde eram selecionadas belas e jovens crioulas para serem vestidas como alegorias índias. Esses índios tão frequentes nas alegorias são idealizações de um passado prévio à chegada do europeu, que, contudo, não acham conexão com os grupos indígenas existentes ou que participaram nas guerras de independência. ${ }^{11}$

As alegorias da índia como pátria viram as primeiras alternativas de substituição dos símbolos espanhóis e as primeiras tentativas de achar uma identidade própria. No caso colombiano, vai até a terceira década do século XIX, quando decresce a temática e triunfa a representação da república como uma mulher de roupas gregas.

\section{Da imagem do rei à imagem do pai da pátria}

Bolívar será o herói por excelência e um dos personagens mais representados nas artes. Suas imagens são contadas em centenas, realizadas em diferentes épocas e países, da Europa até a América, destacando a Colômbia, a Venezuela, o Equador, o Peru e a Bolívia como as de maior produção iconográfica. A circulação das imagens sobre Bolívar aconteceu bem cedo, desde a segunda década do século XIX, com a Campanha Admirável, quando sua fama começou a crescer. ${ }^{12}$

\footnotetext{
${ }^{11}$ No caso da Nova Granada, a contradição inerente na percepção dos indígenas é evidente. Em 1812, por exemplo, Francisco José de Caldas descreveu os nativos colombianos como bárbaros preguiçosos, embora um ano antes tivesse jogado a culpa de sua degradação não na preguiça, mas no mau governo espanhol. Essa situação é contraditória e enxergada claramente no ato de federação das Províncias Unidas da Nova Granada, escrito em 1811, que chamou as "tribos vagantes ou nações de índios bárbaros" de "legítimos e antigos proprietários" da região: os indígenas eram ao mesmo tempo legítimos proprietários e bárbaros. Rebecca Earle, "La iconografía de la independencia en la Nueva Granada". In: Memorias del VII Simposio sobre la Historia de Cartagena: la ciudad en la época de la independencia 1808-1821, Cartagena, CD-ROM, 2007, p. 14.

${ }^{12}$ Já é possível encontrar registros pictóricos sobre Bolívar, como o episódio mencionado no Diário de Caballero de 1815: "A 7 morreu a cidadã Ignacia Paris, mulher do tenente-governador Ignacio Vargas, apelidado o Maneta, uma das melhores moças de Santa Fé, e que gastava um completo luxo. Ela sabia montar muito bem a cavalo, moça completa, de gosto e grande patriota. Numa corrente carregava o retrato de Bolívar." Caballero, op. cit., p. 187.
} 
Figura 5. Pedro José Figueroa. Bolívar Libertador e Pai da Pátria. Óleo sobre tela, $125 \times 95 \mathrm{~cm}$. Museu Quinta de Bolívar - Ministerio de Cultura de Colômbia. Bogotá. 1819.

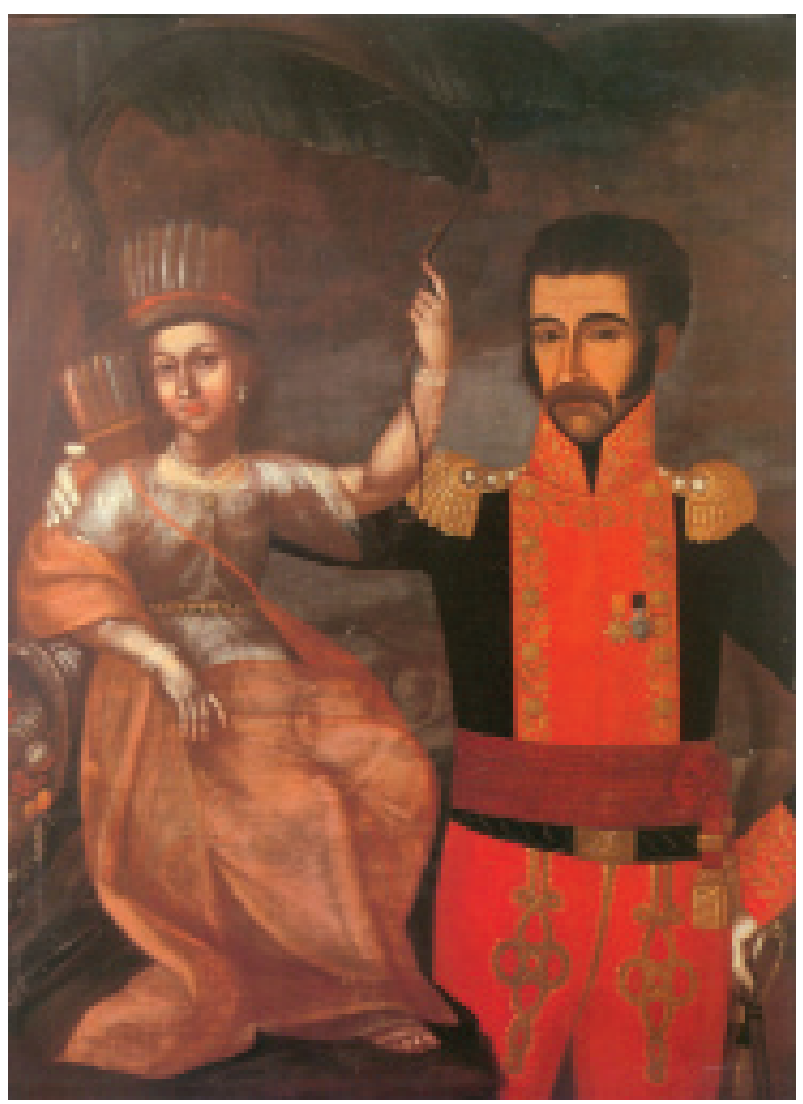

São famosos os retratos de Pedro José Figueroa, que pinta Bolívar pela primeira vez como libertador e presidente da República em $1819 .{ }^{13}$ Nesse ano, Figueroa realizaria a tela Bolívar Libertador e Pai da Pátria, obra alegórica que mostra o herói com traje militar abraçando uma figura feminina, uma índia ricamente adornada que representa a América, coroada com cocar de penas, armada de arco e setas, sentada sobre um caimão e encostada em uma cornucópia, com

${ }^{13}$ Pedro José Figueroa foi descendente do famoso clã de pintores coloniais, os Figueroas. Mestre de José Manuel Groot, Luís García Hevia e muitos outros, que desde setembro de 1819 até 1835 dedicou-se a realizar uma iconografia destinada a celebrar um Bolívar triunfante. 
uma bananeira no fundo (Figura 5). Essa obra foi completada por Figueroa em um prazo de dois meses para a homenagem preparada a Bolívar em Bogotá no mês de outubro de 1819 .

[...] La Asamblea de Notables, encabezada por José Tiburcio Echavarría, quiso agasajar a Bolívar y a sus tropas después del triunfo de Boyacá, para lo cual creó una condecoración: la Cruz de Boyacá y dispuso la realización de una pintura: "Baxo del Dosel del Cabildo de la Ciudad, será colocado un quadro emblemático, en que se reconocerá la LIBERTAD sostenida por el brazo del General Bolívar [...]. ${ }^{14}$

Esse retrato foi apresentado por Dolores Vargas, futura esposa do general Rafael Urdaneta, em um tablado na praça principal para a homenagem ao libertador em setembro de $1819 .^{15}$

Originalmente, Figueroa não estava fazendo um retrato de Bolívar, era pintor no vice-reino restaurado (1815-1819) e estava executando uma pintura totalmente diferente, provavelmente um retrato alegórico comemorativo. Ao mesmo tempo, estava acontecendo a Batalha de Boyacá em agosto do ano 1819.

O que a pintura nos mostra é revelador: ao virar a obra $90^{\circ}$ à direita, descobrimos um pentimento, ${ }^{16}$ uma face que emerge através das roupas da índia. Alguns autores, entre os quais me incluo, consideram que a face do pentimento corresponde ao general Pablo Morillo; outros apoiam a ideia de que a face é do rei Fernando VII (Figura 6). ${ }^{17}$

${ }^{14}$ Rey Márquez, op. cit., p. 4.

${ }^{15}$ Alberto Urdaneta, "Esjematología o ensayo iconográfico de Bolívar". Papel Periódico Ilustrado, ano II, n. 46-48, 1883, p. 422.

${ }^{16}$ Pentimento é uma alteração em um quadro que manifesta uma mudança da ideia do artista naquilo que estava pintando. A palavra seria sinônimo de arrependimento. Os pentimentos podem ser vistos em processos de restauração, raios $\mathrm{X}$ e fotografias infravermelhas, entre outros métodos modernos.

${ }^{17} \mathrm{O}$ debate sobre a identificação da face do pentimento ainda não foi resolvido: para especialistas como Santiago Londoño Vélez e Beatriz González, corresponde ao rei Fernando VII; autores como Alberto Urdaneta e mais tarde Enrique Uribe White consideraram que era um retrato do general Pablo Morillo, hipótese que pessoalmente compartilho, já que Figueroa realizou vários retratos do general espanhol, como o que esta conservado no Museu Nacional de Colômbia. Independentemente do indivíduo retratado, a alusão ao poder espanhol é evidente na obra. Consultar: Santiago Londoño Vélez, Arte colombiano 3.500 años de historia, Bogotá, Villegas, 2001; Beatriz González, "Las artes plásticas en el siglo XIX". In: Darío Jaramillo Agudelo (diretor acadêmico), Gran enciclopedia de Colombia. Temática 6 Arte, Bogotá, Círculo de Lectores, 1993, p. 94; Urdaneta, op. cit., p. 422; Enrique Uribe White, Iconografía del libertador, 2. ed., Bogotá, Lerner Ltda., 1983, p. 75; Yobenj Aucardo Chicangana-Bayona, La independencia en el arte y el arte en la independencia, 
Figura 6. Esquerda: detalhe do pentimento. Pedro José Figueroa. Bolívar Libertador e Pai da Pátria. Óleo sobre tela, $125 \times 95 \mathrm{~cm}$. Museo Quinta de Bolívar - Ministerio de Cultura de Colombia. Bogotá. 1819. Direita: Pedro José Figueroa. Retrato do general Pablo Morillo. Óleo sobre tela, 125,5 x $79 \mathrm{~cm}$. Museo Nacional de Colombia. Bogotá. Ca. 1815. Reg. 524. Foto: ( Museo Nacional de Colombia / Juan Camilo Segura.
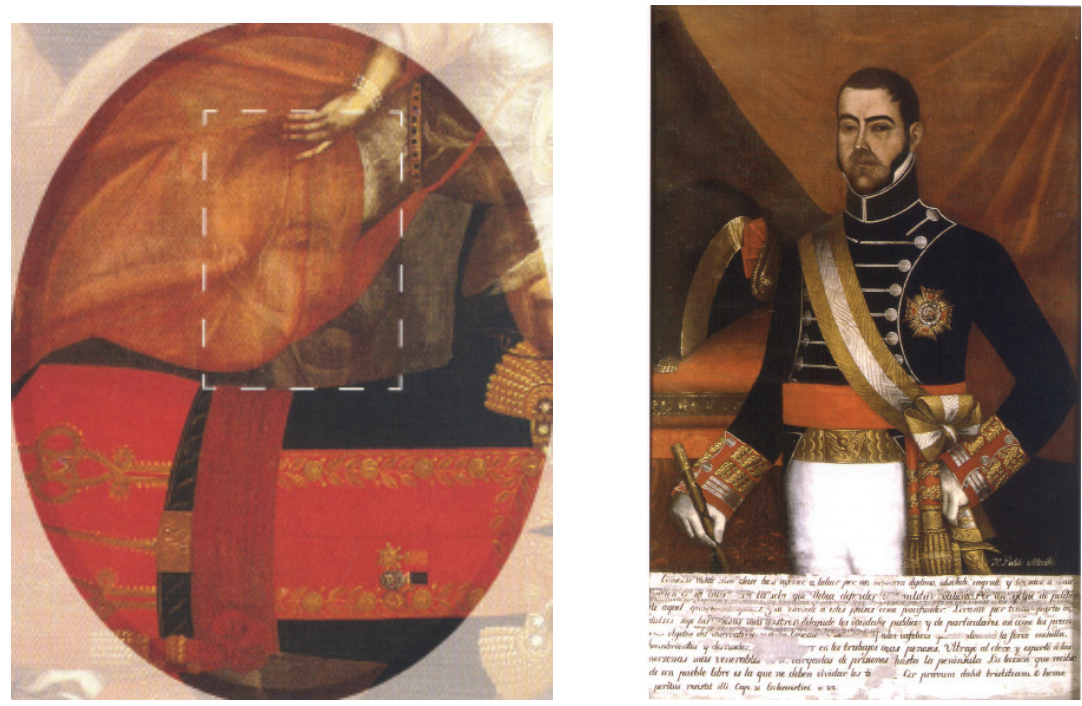

Pedro José Figueroa devia estar executando por encomenda um retrato comemorativo, provavelmente antecipando o resultado da guerra ou a expectativa realista de vitória em alguma batalha. Tal pintura acabou sendo abortada e, da mesma forma que se acostumou na colônia, o pintor reutilizou a tela. Figueroa deixaria na pintura de 1819 , sem pretender isto, um testemunho do conflito político. A chegada de um novo poder republicano em substituição ao domínio espanhol era o nascimento visual de Bolívar como "Pai da Pátria" em substituição às imagens do "Rei Pai". Quintero Esquivel se refere à mudança das imagens do Rei Pai pelas do Pai da Pátria:

Bogotá, Ministerio de Educación Nacional, 2009, p. 17; "Contando una historia nacional: la configuración de la iconografía sobre la independencia 1830-1880”. In: Las historias de un grito. Doscientos años de ser colombianos, Bogotá, Museo Nacional de Colombia, 2010, p. 40. 
[...] Con la llegada de Bolívar encamino a la Campaña del Sur se sustituyó en la conciencia colectiva la metáfora del rey padre, por una nueva: el padre de la patria, figura idealizada que se recibió con banderas y pendones de damasco y arcos triunfales. Era una excitación pasajera que aún se renueva en los actos rituales donde no se ha consolidado el Estado [...]. ${ }^{18}$

Com relação às dinâmicas visuais das pinturas, são bastante pertinentes as palavras de Esther Acevedo:

[...] La multiplicidad de vocabularios y estrategias visuales que se dan en estas pinturas son el correlato de las distintas miradas perceptivas de los grupos sociales, que varían según los espacios regionales o sociales en que se inscribian y que se fueron transformando a lo largo del tiempo. La elección de una u otra estrategia formal o de contenido nos develará tanto las ideas que sobre la historia tenía el patrocinador de la obra, como el desarrollo de la sociedad a laque se proponía convencer [...]. ${ }^{19}$

Por outro lado, apesar das mudanças políticas e ideológicas, Figueroa continua como pintor da Nova República (assim como seus filhos), sendo um dos principais retratistas de Bolívar nessa época. Figueroa pinta retratos de espanhóis como Morillo e depois realiza retratos de Bolívar e Santander, pois se trata de encomendas, contratos e trabalhos remunerados. Essa flexibilidade lhe permitiu sobreviver à transição entre guerras. Outros pintores que se comprometeram com a causa independentista ou realista deixaram os pincéis e tomaram as armas. ${ }^{20}$

\section{A Constituição substitui o rei}

O retrato de Francisco de Paula Santander realizado por Espinosa em 1853 é bastante particular, não correspondendo a um retrato como tal, mas à representação de um personagem, à encenação de um mito, uma lenda, um semideus. Essa pintura é uma homenagem póstuma de Espinosa ao general Santander, que aparece de corpo inteiro, em traje militar, o que lhe dá um caráter épico e monumental, leitura reforçada pelas cenas bélicas usadas como pano de fundo (Figura 7).

\footnotetext{
${ }^{18}$ Jorge Eliécer Quintero Esquivel, "La independencia en el Gran Cauca, Mariquita y Neiva”, Revista Credencial Historia 243, mar. 2010, p. 14.

${ }^{19}$ Acevedo, op. cit., p. 115.

${ }^{20}$ Eugenio Barney-Cabrera, "Manifestaciones artísticas en tiempos revueltos". In: Historia del arte colombiano, Bogotá, Salvat, 1975, v. IX, p. 1.234.
} 
Mas a questão mais importante na imagem é que o general Santander sustenta no alto a Constituição, sendo esse o ponto central da pintura. Espinosa dá o maior destaque a esse documento, como suprema autoridade. Sobre a importância da sacralização da Constituição, Margarita Garrido comenta:

[...] la República se vincula a lo sagrado: el monismo eclesiástico-imperial es reemplazado por el vinculo entre religión y patria. En las ceremonias públicas la Constitución ocuparía el lugar del rey y sería también la fuente de honor. Éste ya no vendría de la relación con el rey sino de los derechos otorgados por la Constitución a los ciudadanos [.... ${ }^{21}$

Figura 7. José María Espinosa Prieto. Francisco de Paula Santander. Óleo sobre tela, $228 \times 145 \mathrm{~cm}$. Colección particular. Museo Nacional de Colombia, Bogotá. 25 de mayo de 1853. Reg. 243.Foto: @Museo Nacional de Colombia /Juan Camilo Segura.

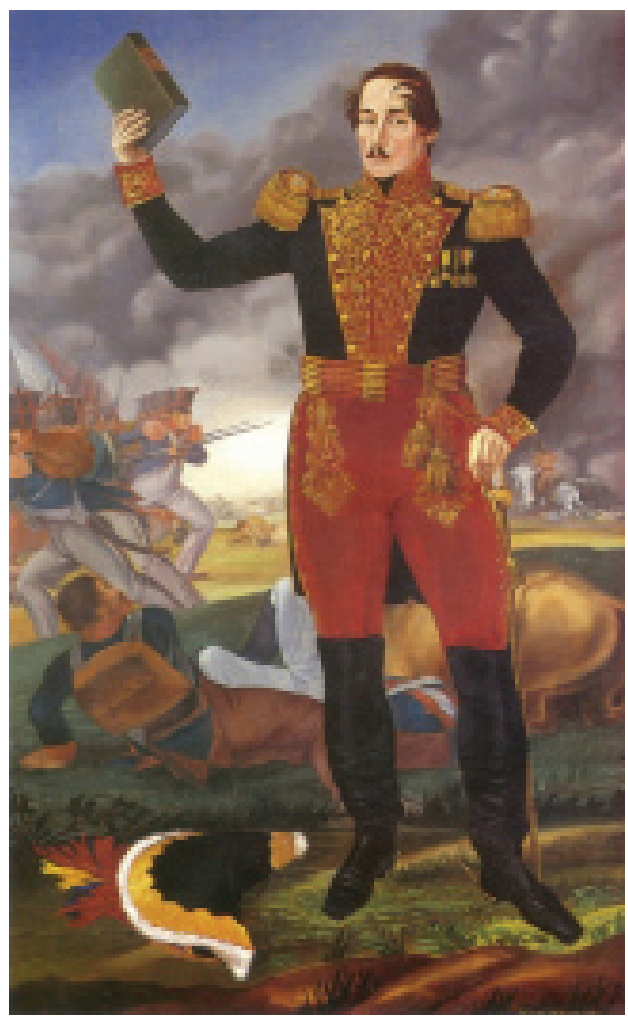

${ }^{21}$ Margarita Garrido, "Nueva Granada entre el orden colonial y el republicano: lenguajes e imaginarios sociales y políticos". In: Marco Palacio Rozo (coord.), Las independencias hispanoamericanas. Interpretaciones 200 años después, Bogotá, Norma, 2009, p. 116. 


\section{As imagens dos heróis, os modelos do cidadão}

O recrudescimento das guerras de independência, especialmente após o ano 1815, com a reconquista, aumentou o número de execuções e mortes de patriotas, criando mártires cujas histórias serviram para elevar o moral dos que continuavam na luta. Tentou-se transformar esses mártires em exemplos de virtude e modelos a serem imitados para enaltecer a pátria e promover sacrifícios em função de ideais patrióticos. Pela pátria, qualquer sacrifício era pouco para um verdadeiro cidadão, como já proclamavam os discursos republicanos desde $1810 .^{22}$ Representava a "Mãe pela qual devia-se viver e morrer e a quem cabe lealdade, respeito e honra.". 23

O engrandecimento e a idealização do indivíduo que serve e sacrifica sua vida pela pátria acabam sendo transformados em modelo a imitar e render culto por seus fatos notáveis; assim surgem como tema na iconografia sobre a independência. O herói é construído e consolidado em detrimento do povo, do coletivo, porque, ao idealizar valores e virtudes em um único indivíduo excepcional, retorna-se a uma tradição clássica de homens semideuses, com atributos excepcionais físicos e morais que são predestinados a guiar as massas e mudar o mundo; sua consagração e culto como heróis oculta a participação coletiva nos acontecimentos históricos.

[...] Los héroes son símbolos poderosos, encarnaciones de ideas y aspiraciones, puntos de referencia, soportes de identificación colectiva. Son, por eso, instrumentos eficaces para llegar, al servicio de la legitimación de regímenes políticos, a la cabeza y el corazón de los ciudadanos $\left[\ldots . .{ }^{24}\right.$

Mas como adverte José Murilo de Carvalho, o herói, por ser fruto de um processo de elaboração coletiva, diz mais da sociedade que o produz que sobre si mesmo. O indivíduo de carne e osso, do qual surge o herói, não é o mesmo que

\footnotetext{
${ }^{22}$ No começo do século XX, os manuais escolares continuaram exaltando o valor do martírio e o sacrifício pela pátria: “¡Cuán hermoso es morir por la Patria, por más terrible que parezca el modo como rindieron su vida nuestros próceres! El sacrificio de la vida por ella es uno de los menores que debemos hacerle.... Jesús María Henao \& Gerardo Arrubla, Historia de Colombia para la enseñanza secundaria, Bogotá, Escuela Tipográfica Salesina, 1911, t. II, p. 129.

${ }^{23}$ Garrido, op. cit., p. 105.

${ }^{24}$ José Murilo de Carvalho, La formación de las almas. El imaginario de la República en el Brasil, Buenos Aires, Universidad Nacional de Quilmes, 1997, p. 81.
} 
termina idealizado e imortalizado como modelo de virtudes pela tradição e pela historiografia.

Os heróis já tinham ganhado vida de modo efêmero no teatro e nas homenagens das festas civis nos primeiros tempos da República. Desde a segunda década do século XIX, começaram também a ser temas de desenhos, pinturas e gravuras. Os artistas representavam heróis humanizados, que também tiveram infância, juventude e morreram, mas que por suas façanhas permaneceram na memória como modelos de virtudes republicanas.

A conformação dessas primeiras galerias de heróis da Independência tem a particularidade não só de apresentar os momentos da glória militar, mas também destina desenhos para mostrar o cotidiano da infância e mocidade de personagens como Antônio Ricaurte (1786-1814) ou José María Córdova (1799-1829), no caso deste último representado em uma aquarela por Jose María Espinosa como uma criança em seus primeiros anos, brincando em um cavalinho de pau, prevendo seu futuro como militar. Espinosa mesmo tinha lutado ao lado do herói na batalha do Río Palo em 1815.

Desde a tradição colonial era comum representar nas pinturas o momento último dos santos e mártires. Isso tinha uma justificação, pois era a morte e não o nascimento a data mais importante na vida dos cristãos. O culto aos heróis e especialmente aos mártires da Independência achará muitos pontos em comum com os santos do cristianismo, mas também com a tradição clássica grego-romana dos semideuses. O herói da Independência, quase divinizado e desumanizado, finalmente também morre. Por meio da imagem, sua vida é perene; desse modo, eles são representados nas pinturas de maneira testemunhal e como homenagem a seus últimos momentos.

Nas ocasiões em que a morte do herói acontece em espaços abertos, florestas, clareiras ou estradas, como no caso do marechal Sucre ou do general Córdova, a representação tem uma conotação dramática de denúncia, ao mostrar jovens heróis assassinados traiçoeiramente por homens indignos e covardes que agem em meio às sombras.

Um desses casos é o do general José María Córdova, herói de Ayacucho, que se rebela contra a ditadura de Bolívar e termina assassinado traiçoeiramente aos 30 anos pelo comandante irlandês Rupert Hand no sábado, 17 de outubro de 1829, em Santuário, Antioquia. Em algumas pinturas e gravuras, aparece seu 
corpo sem vida, acompanhado por três coroas de louros, emblemas de suas grandes vitórias em batalha, ${ }^{25}$ e mais ainda de seus valores morais como herói republicano: Virtude, Perseverança e Devoção à Pátria. Sobre o corpo sem vida do herói, voa um anjo, uma vitória que lhe faz as honras e segura uma folha de palmeira, símbolo do martírio na iconografia cristã, que é reapropiado conscientemente para estabelecer um paralelo entre os primeiros próceres em prol da liberdade e da República e os mártires cristãos.

O outro caso é a representação da morte de Antônio José de Sucre (17951830), nativo de Cumaná e vencedor das batalhas de Pichincha e Ayacucho, além de primeiro presidente da Bolívia e potencial sucessor de Bolívar. O marechal, de 35 anos, foi assassinado por tiros na sexta-feira, 4 de junho de 1830, nas montanhas de Berruecos pelo caminho a Cabuyal. Lá o aguardavam os assassinos, Apolinar Morillo, José Erazo, Juan Gregorio Sarria e três parceiros mais, que em teoria tinham sido contratados pelo general José María Obando, comandante das tropas do Cauca, e pelo general equatoriano Juan José Flores, embora nunca se comprovasse se realmente foram os autores intelectuais do assassinato. ${ }^{26}$

Pedro José Figueroa pintará uma das suas últimas obras, A Morte de Sucre, em 1835, cinco anos após o assassinato do general. Nessa pintura de estilo primitivo e ingênuo, ${ }^{27}$ ele representa nos primeiros planos o marechal derrubado por um tiro na testa, enquanto sua montaria foge apavorada. Na parte superior

${ }^{25}$ A batalha mais famosa da qual participou Córdova seria Ayacucho, em 1824, pela qual seria chamado "o Herói de Ayacucho"; porém, lutou também nas batalhas de Río Palo (1815), Pantano de Vargas (1819), Boyacá (1819), Choros Blancos (1820), Sabanas de Corozal e da tomada de Cartagena (1820) e Pichincha (1822).

${ }^{26}$ Ao conhecer a terrível notícia do assassinato, Bolívar exclamou: “Dios excelso! Se ha derramado la sangre del inocente Abel... La bala cruel que le hirió el corazón, mató a Colombia y me quitó la vida." A Gaceta de Colombia de 4 de julho de 1830 se refere à trágica morte do marechal nos seguintes termos: "El día 4 de junio en la montaña de Berruecos cerca de Pasto, recibió una descarga de fusilería que lo privó de la vida. El Prefecto y Comandante General del Cauca están (en 1830) practicando las diligencias más activas en el descubrimiento y persecución de los asesinos. ¡A sí murió a los 35 años de edad el vencedor de Ayacucho! ¡Así acabó su vida corta, pero tan llena de merecimientos! Si hubiera exhalado su espíritu sobre el teatro de la victoria; con su último aliento habría dado gracias al cielo de haberle reservado una muerte gloriosa; pero asesinado cobardemente en una oscura montaña, él deja á su patria el deber de perseguir esta alevosía, y de adoptar medidas que corten nuevos escándalos y la repetición de escenas tan lamentables como oprobiosas."

${ }^{27}$ Essas obras são caracterizadas pela espontaneidade, pelo trabalho autodidata dos artistas, pelas cores brilhantes e contrastadas e pelo uso de uma perspectiva captada por intuição. São obras, em muitos casos, distantes da aprendizagem acadêmica. 
esquerda, entre os arbustos, emergem os quatro assassinos; ao seu lado, um felino com flores; e, ao fundo, aparece Lorenzo Caicedo, ajudante de Sucre.

O felino representado e a data da pintura (1835) são importantes para entender o contexto da obra e como esta adquire um caráter de denúncia política. Nesse mesmo ano, José María Obando apresentava novamente sua candidatura à Presidência da República de Nova Granada. Ele era apontado como o autor intelectual do assassinato de Sucre, e seu apelido era "Tigre". Essa é a razão por que Figueroa colocou sutilmente o felino na pintura. As flores que coroam o bicho na pintura fazem alusão ao general equatoriano.

A morte do herói, de modo violento ou por causas naturais, é o fim de sua vida na Terra, o final romântico da sua jornada épica. É a conclusão de uma vida dedicada à liberdade e à pátria, em que os interesses próprios e individuais são deixados de lado pelo bem coletivo da sociedade. São vidas idealizadas pela tradição e pela arte, são os novos santos da República, modelos morais e éticos para seguir como exemplo (Figura 8).

Figura 8. Esquerda: Anônimo. Córdova Morto, gravura francesa iluminada. Fondo Anselmo Pineda. Biblioteca Nacional de Colômbia, Bogotá, século XIX. Direita: Pedro José Figueroa, A Morte de Sucre, óleo sobre tela, 139,5 × 200 cm. Coleção Banco de la República, Bogotá, ca. 1835.
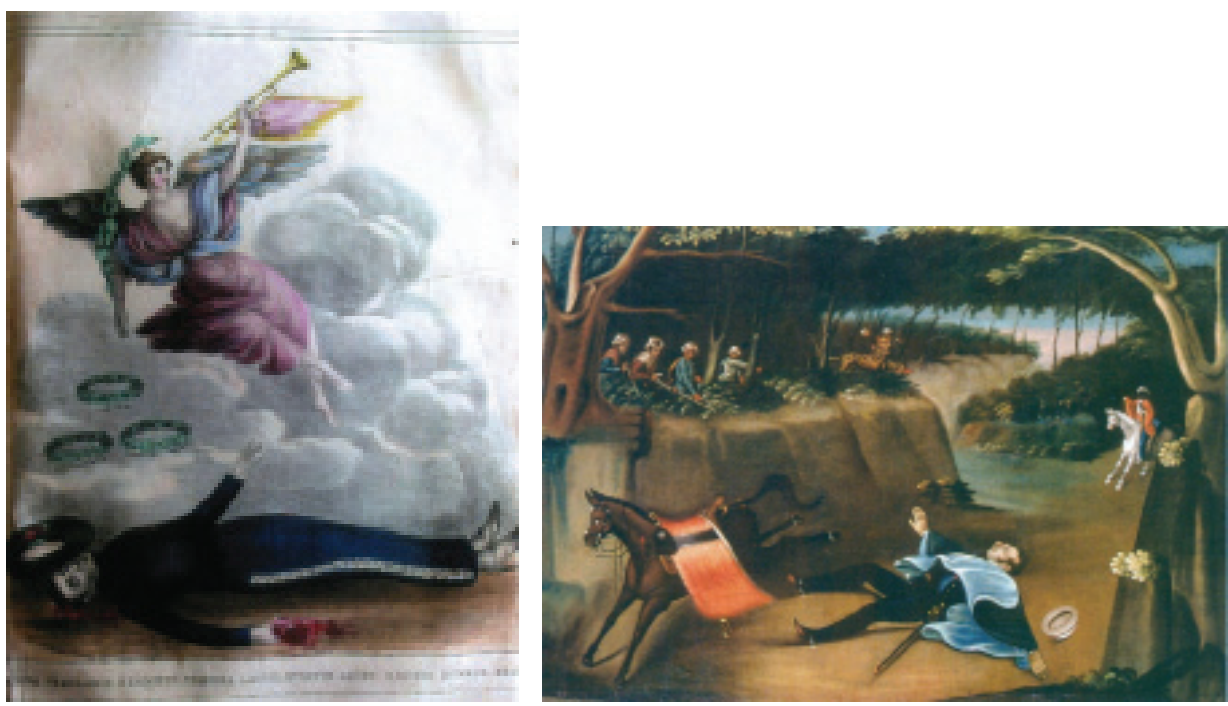
Também há cenas da morte dos heróis representadas em espaços interiores, em amplas camas, como é o caso do general de Santander, acompanhado de seus amigos, parentes e partidários, ao melhor estilo das cortes dos reis. Em alguns casos mais estranhos, como na morte de Antônio Nariño, este é representado sentado esperando o momento da sua morte (Figura 9).

Figura 9. Esquerda: Pedro José Figueroa (atribuído), Antonio Nariño ao momento da sua morte. Óleo sobre tela, $116 \times 87 \mathrm{~cm}$. Museo de la Independencia

- Casa del Florero. Ministerio de Cultura de Colombia, Bogotá, 1838. Direita: Luís García Hevia, A Morte de Santander. Óleo sobre tela, $205 \times 163 \mathrm{~cm}$. Museo Nacional de Colombia, Bogotá.1841. Reg. 553. Foto: @Museo Nacional de Colombia /Juan Camilo Segura.
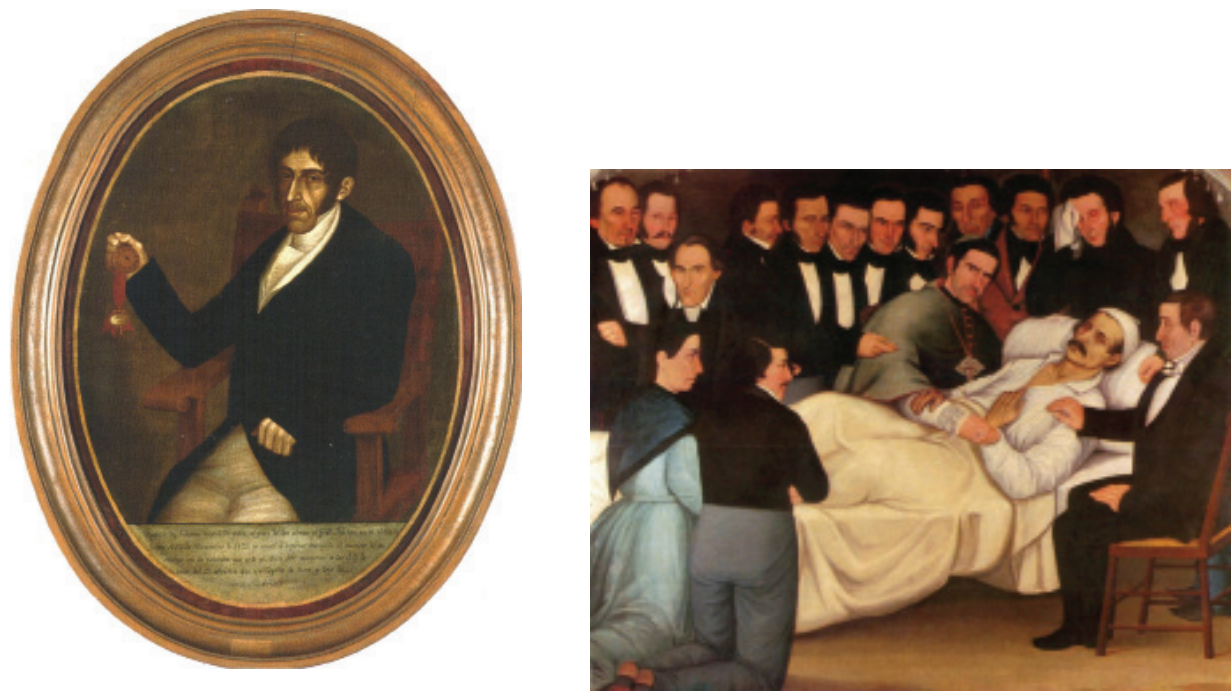

Dentro da iconografia da morte dos heróis pátrios, a do general Antonio Nariño é das mais curiosas: uma pintura a óleo, de Pedro José Figueroa, de 1838, mostra o momento da morte do general moribundo, sentado em uma cadeira. $\mathrm{O}$ prócere tem na sua mão um relógio. O quadro traz o texto "Depois de despedir-se para o país das almas o general Nariño na Villa de Leyva em 12 de dezembro de 1823 se sentou a esperar tranquilo o instante da sua morte na posição em que se vê. Veio aquele momento às 5 da tarde do dia 13, advertiu que tinha chegado a hora e deixou de existir." 
A morte do general Francisco de Paula Santander acontece em seu quarto, deitado na cama, por causa de uma afecção hepática em 1840. O herói aparece acompanhado pelos partidários, parentes, assistido pela ciência e pela religião. A cena é serena e tranquila, uma homenagem e despedida ao presidente da República, no melhor estilo daquelas que as cortes europeias faziam para os grandes reis e imperadores. O cadáver sem vida também está relacionado com a purificação do corpo e a entrega final a Deus. A importância da representação da morte de Santander cobra relevância por ser o falecimento do mais destacado herói das guerras de Independência e governante até esse momento. Bolívar já tinha morrido fazia uma década. A pintura de García Hevia, de 1841, sobre o episódio, além da cena, é um retrato coletivo.

A imagem do herói é resultado de uma fabricação posterior, uma construção da memória realizada por gerações subsequentes que, conforme diferentes circunstâncias, dão importância a certas virtudes e valores que consideram representados em certos indivíduos e que deveriam ser características do cidadão ideal. Os valores do herói mudam com o tempo e com as gerações que lhes rendem culto.

Os heróis construídos respondem a uma necessidade ou aspiração coletiva, a modelos de comportamento valorizados. Para poderem ser manipulados por grupos ou elites, é necessário que tenham raízes, precisam de um terreno social e cultural do qual se alimentar, isto é, uma comunidade de sentido. Essa é a relação que diferencia os projetos bem-sucedidos de construção de heróis e explica, também, os que fracassam, ou os que não conseguem o status de heróis nacionais.

Miguel Leonidas Scarpetta e Saturnino Vergara, a propósito da Exposição Nacional de 20 de julho de 1871, comentaram a importância das pinturas de próceres como testemunhas e memória de um passado fundacional:

[...] Y comoquiera que la galería de retratos de nuestros Padres de la Patria están en primer término, diremos: que aun cuando en su mayor parte no tienen mérito artístico, si merecen figurar, con orgullo de nuestra parte, en la Exposición, sea porque este gran certamen de manufacturas, artes, productos naturales etc. se abrió el 20 de julio de 1871, día de regocijo popular en memoria de nuestro primer paso en la vía peligrosa de la emancipación de nuestros déspotas gobernantes españoles; o bien porque estas 
figuras deben pasar de generación en generación como enseña el heroísmo y virtudes republicanas $[. . .]^{28}$

As pinturas, as gravuras e os desenhos dos heróis são uma forma de promover os valores republicanos e conseguir chegar, por meio das imagens, a um público mais amplo. Porém nem sempre havia oportunidade para ver essas obras, só nas exposições que eram organizadas. Serão os manuais de História, os livros, as estampas e as notas de dinheiro os meios que farão essas imagens familiares para a sociedade. ${ }^{29} \mathrm{O}$ sucesso de um herói, de um tipo de modelo de virtudes, podia medir-se conforme sua integração no imaginário popular nacional, assim como aponta José Murilo de Carvalho:

[...] Por medio del imaginario se puede llegar no sólo a la cabeza sino, de modo especial, al corazón, esto es, las aspiraciones, los miedos y las esperanzas de un pueblo. Es en él donde las sociedades definen sus identidades y objetivos, definen sus enemigos, organizan su pasado, presente y futuro [...]. ${ }^{30}$

A maior produção pictórica durante os séculos XIX e XX está dedicada aos retratos dos heróis e dos notáveis da República. O que se percebe nas obras está associado ao contexto histórico do país, infestado de guerras civis onde a facção política, o grupo de poder, exclui o coletivo, por isso o herói é o protagonista. ${ }^{31}$ Dessa perspectiva, as ações épicas que levaram à Independência não dependem do coletivo, mas de indivíduos, e isso explica em parte a proliferação de retratos. A pintura como auxílio documental representa essa visão ideológica da História, cujo motor são os indivíduos, primeiro os heróis militares e depois seus herdeiros, os notáveis da República.

\footnotetext{
${ }^{28}$ Scarpetta \& Vergara, "Breve noticia de las pinturas, dibujos y esculturas presentados en la Exposición Nacional del 20 de julio de 1871". In: Álvaro Medina, Procesos del arte en Colombia, Bogotá, Instituto Colombiano de Cultura, 1978, p. 221.

${ }^{29}$ As imagens de La Pola, Bolívar, Nariño, Santander e Camilo Torres, levadas a cabo por José María Espinosa, viraram referências para as imagens dos manuais de História, das notas e das moedas correntes. É a partir das litografias francesas da década de 40, baseadas nas suas obras, que também se permitiu recriar obras pictóricas, gráficas e audiovisuais durante o século XX.

${ }^{30}$ Carvalho, op. cit., p. 17.

${ }^{31}$ Marta Traba, Historia abierta del arte colombiano, Bogotá, Colcultura, 1984, p. 50.
} 


\section{Policarpa Salavarrieta como sujeito político}

Em um universo heroico majoritariamente masculino, as mulheres que participaram como financiadoras, informantes, enfermeiras, cozinheiras, auxiliares, mensageiras e combatentes, muitas das quais morreram, também ganham uma pequena representação no panteão nacional de heróis sobre a gesta emancipadora. Algumas das mulheres destacadas nas pinturas e esculturas serão Policarpa Salavarrieta (1795-1817), Manuelita Sáenz (1797-1856), Carmen Rodríguez de Gaitán (1777-1852) e, tardiamente, Antonia Santos (1782-1819).

Policarpa Salavarrieta é a heroína por excelência, sendo tema dos retratos dos pintores José María Espinosa (1855-1857), Epifanio Garay (ca. 1890), Celestino Martínez (1850), Roberto Páramo (1910), Samuel Velásquez (ca. 1920) e Ricardo Acevedo Bernal (1917), entre muitos outros. A partir de meados do século XIX e especialmente com o primeiro centenário da Independência (1910) e o primeiro centenário da sua morte (1917), multiplica-se consideravelmente sua iconografia e sua efígie vira emblemática da participação da mulher na gesta da Independência, sendo ao mesmo tempo uma imagem que exclui outras mulheres e outras formas de participação.

A descrição literária mais antiga sobre La Pola é feita por José María Caballero em seu diário, a respeito de seu aspecto físico e de sua morte em 14 de novembro de 1817:

[...] A 10, le hicieron consejo de guerra a La Pola y a quince de sus compañeros, por un plan que dicen había hecho para mandar a los Llanos, donde los patriotas. Era esta muchacha muy despercudida, arrogante y de bellos procederes, y sobre todo muy patriota; buena moza, bien parecida y de buenas prendas. Salió en medio de los demás presos, sus compañeros. Iba en camisón de zaraza azul, mantilla de paño azul y sombrero cubano... y al pueblo dijo: "¡Pueblo de Santa Fe! ¿Cómo permitís que muera una paisana vuestra e inocente?". Y después dijo: "Muero por defender los derechos de mi patria". Y exclamando al cielo, dijo: "Dios eterno ved esta injusticia!" Dijo y exclamó otras cosas dignas de memoria. Así murió con seis crueles balazos. ¡Dios haya tenido misericordia de su alma! ;Así se cumplen los indultos generales, despedazando cruelmente el pecho tierno de esta heroina, de esta mártir de la patria, de esta constante e incomparable mujer! [...]..$^{32}$

\footnotetext{
${ }^{32}$ Caballero, op. cit., p. 244.
} 
A representação de La Pola de pele branca, vestido azul e chapéu, descrita por Caballero, será o modelo para os retratos da heroína durante o século XIX. Outra fonte será o relato de Andrea Ricaurte, que ajudou e escondeu La Pola; esta é uma das primeiras fontes que a descrevem fisicamente:

[...] Policarpa era joven y bien parecida, viva, inteligente, un color aperlado. El joven Bibiano se le parecía. Pero era tardón para hacer las cosas, con la llegada de Policarpa los trabajos políticos se aceleraron, y como ella no era conocida en la ciudad, salía y andaba con libertad, facilitaba la correspondencia con las juntas y las guerrillas. Apareció como auxiliar de Sabaraín y otros que estaban de soldados por insurgentes; los postas eran más frecuentes, pero las pesquisas y los patíbulos se aumentaban [...]..$^{33}$

Outra fonte muito importante na construção da iconografia sobre La Pola, especialmente o episódio do patíbulo ao lado do confessor e rodeada de soldados, segundo Beatriz González, foi a peça teatral de José María Domínguez, La Pola. Tragédia em cinco atos. Essa obra foi escrita em 1820 a pedido do general Francisco de Paula Santander, como uma forma de celebrar o 20 de julho lembrando os terríveis anos da Pacificação e para manter na memória o exemplo de Policarpa Salavarrieta. A obra seria publicada em 1826 e representada em 20 de julho de 1820 , de 1826 e de 1836 . Essa obra teatral foi inspirada por Domínguez na sua vivência pessoal, no diário de Caballero e no relato de Andrea Ricaurte. ${ }^{34}$

A primeira imagem conhecida de La Pola é uma pintura anônima de 1825 intitulada Policarpa Salavarrieta Marcha ao Suplício, que representa a heroína de Guaduas recebendo consolo do padre com um crucifixo, enquanto um soldado espanhol a leva ao patíbulo (Figura 10). De um lado da pintura se enxerga o estrado onde acontecerá o fuzilamento. No canto esquerdo inferior aparece uma epígrafe que diz: "Policarpa Salavarrieta sacrificada pelos espanhóis nesta praça em 14 de novembro de 1817. Sua memória eterniza entre nós e sua fama ressoa de

\footnotetext{
${ }^{33}$ Em 1918, Saldanha transcreve a descrição levada a cabo por Dona Andrea Ricaurte de Lozano, em 20 de abril de 1875. Foi publicada pelo Boletín de Historia com a autorização do seu filho, Lorenzo María Lozano. E. de Saldanha, "Detalles desconocidos sobre la Pola”, Boletín de Historia y Antigüedades, v. XII, n. 133, fev. 1918, p. 21.

${ }^{34}$ Beatriz González propõe a interessante e sugestiva hipótese de que a iconografia de Policarpa esteve influenciada pela fisionomia de Dona Bárbara Cuervo, que representou o papel de heroína na peça de teatro de Domínguez. Beatriz González, "II. La iconografía de Policarpa Salavarrieta". In: Policarpa 200. Serie Cuadernos iconográficos del Museo Nacional de Colombia $n^{0}$ 1. Exposición conmemorativa del bicentenario del nacimiento de Policarpa Salavarrieta, Bogotá, Museo Nacional de Colombia, 1996, p. 3.
} 
polo a polo." A epígrafe do quadro reforça a função de gerar memória ao comemorar um episódio de martírio acontecido sete ou oito anos antes, mostrando um modelo feminino, um exemplo de virtudes e, finalmente, difundindo a fama da heroína.

Figura 10. Anónimo, Policarpa Salavarrieta. Óleo sobre tela, $74,7 \times 93,5 \mathrm{~cm}$. Colección Museo Nacional de Colombia, Bogotá. ca. 1825.Reg. 555. Foto: ๑Museo Nacional de Colombia /Juan Camilo Segura.

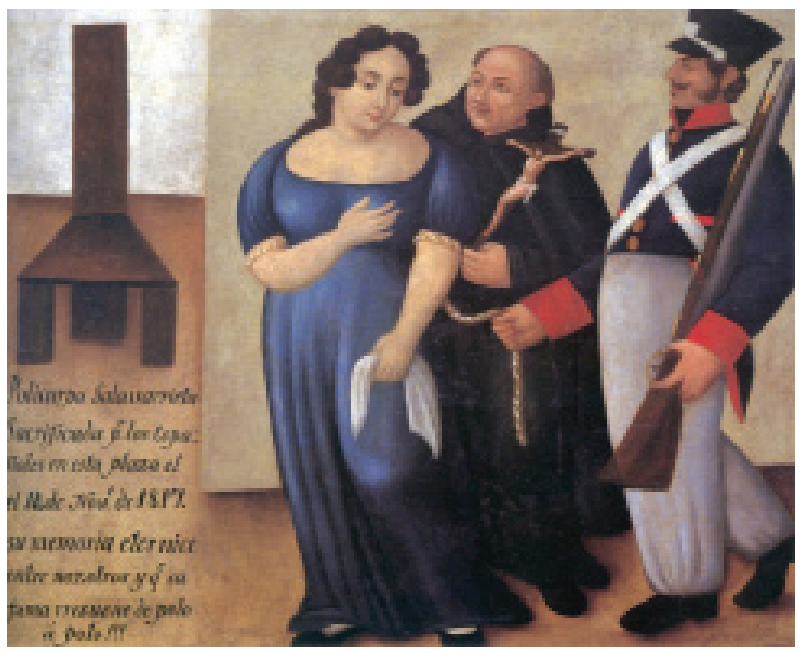

Outra fonte será a obra escrita pelo coronel inglês Hamilton, que visita a Colômbia em 1823 e, de volta ao seu país, edita em Londres, em 1827, um livro em dois volumes intitulado Travels through the interior provinces of Columbia. Nessa obra se faz uma pequena referência a La Pola:

Varios caballeros me contaron en Bogotá... que la conducta de la Pola cuando marchaba al patíbulo causó la admiración pública, pues que ella, sin salirse de las lindes del recato y dignidad debidos a su sexo, mostró firmísimo valor, siendo sus últimas palabras: ¡Que la causa de mis oprimidos compatriotas obtenga el triunfo! ${ }^{35}$

José María Espinosa pintará vários retratos de Policarpa Salavarrieta entre 1855 e 1857 (Figura 11). No retrato de 1855, ela aparece como uma bela jovem, longe de qualquer referência à prisão ou ao patíbulo. La Pola no Cárcere, pintada

\footnotetext{
${ }^{35}$ Saldanha, op. cit., p. 21.
} 
em 1857, é inovadora ao apresentar a heroína durante sua prisão e antes de ir ao sacrifício. A iconografia de La Pola no Cárcere está inspirada nas memórias de José Hilario López, lidas em parte no Colégio do Rosário em 1851. Publicadas posteriormente em $1857,{ }^{36}$ influenciaram toda a iconografia realizada por Espinosa sobre ela. José Hilario López conheceu La Pola e lutou na Campanha do Sul junto com Espinosa e Sabaraín, companheiro da heroína.

Figuras 11. Esquerda: José Maria Espinosa, Policarpa Salavarrieta. Óleo sobre tela $34 \times 24,3$ cm. Museo Nacional de Colombia, Bogotá, 1855. Reg. 2094. Foto: (CMuseo Nacional de Colombia /Juan Camilo Segura. Direita: José María Espinosa. La Pola en Capela. Óleo sobre tela. $80 \times 70 \mathrm{~cm}$. Concejo Municipal, Villa de Guaduas, ca. 1857.
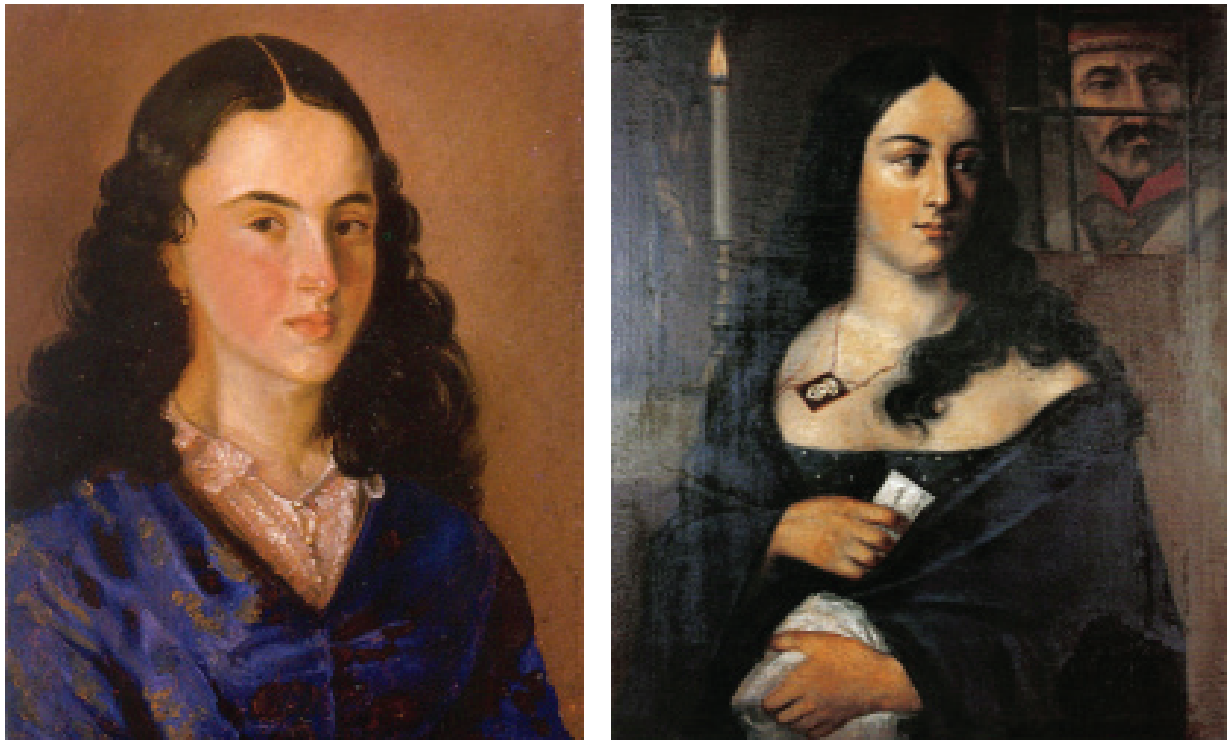

É tal a importância de Policarpa Salavarrieta, sua idealização e sua lembrança na memória, que alguns autores colocam-na do lado de outras grandes heroínas e destacadas mulheres:

Las hazañas como heroina de Policarpa Salavarrieta son comparadas a otras famosas heroínas, tales como la francesa Juana de Arco, las venezolanas Consuelo Fernández, Cecilia Mújica, Juana Ramírez, Eulalia Ramos de Chamberlain y a las ecuatorianas

\footnotetext{
${ }^{36}$ González, op. cit., p. 4.
} 
Manuela Cañizares, Rosa Zárate, a la peruana Andrea Bellindo y a las bolivianas Teresa Basto de Lemoine, Justa Varcha, Bárbara Fernández de Castro entre muchas otras. $^{37}$

A memória de Policarpa Salavarrieta como heroína das guerras de Independência ${ }^{38}$ ganhou importância no fim do século XIX e no começo do século XX, especialmente nos trabalhos de pesquisa da Academia Nacional de História da Colômbia. Sua difusão no Boletim de História e Antigüidades, juntamente com as comemorações dos centenários, reforçou o culto à heroína de Guaduas, em que triunfa a imagem de patriota devota e apaixonada que incita o povo à revolução, especialmente no momento de seu martírio. ${ }^{39}$

Outras heroínas representadas nas pinturas e desenhos foram Manuelita Sáenz, revolucionária e heroína quitenha. Na Colômbia, a lembrança da sua memória foi centrada mais na relação sentimental com Bolívar e em como ela o salvou da conspiração setembrina de 1828. Carmen Rodríguez de Gaitán foi

\footnotetext{
${ }^{37}$ R. Álvarez Guerrero, Policarpa, ¿Una heroína...genio?, Bogotá, Editorial de Cundinamarca Antonio Nariño, 1995, p. 64-84.

38 "Policarpa no había participado en movimientos subversivos antes de 1810, de manera que tenía libre el camino para actuar; además, como tenía dos hermanos en el Convento de los Agustinos, no despertaría sospechas. Su misión consistió en actuar en dos frentes muy concretos: servir de espía y correo entre los contactos auxiliares y los comandos guerrilleros en Casanare; y conquistarse a los patriotas enrolados en las filas realistas para que desertaran y se unieran al ejército que estaban organizando Bolívar y Santander." Alicia Hincapié, Tras la imagen y la presencia de Policarpa, Bogotá, Centro de Historia de la Villa de San Miguel de las Guaduas, 1996, p. 26.

${ }^{39}$ María Restrepo Sáenz e Enrique Ortega Ricaurte, membros da Academia Colombiana de História, em um relatório intitulado La Pola yace por salvar la patria, de 1949, se referem aos momentos finais de La Pola: "La Pola marchó con paso firme hasta el suplicio, y en vez de repetir lo que le decían sus ministros, no hacía sino maldecir a los españoles y encarecer su venganza. Al salir a la plaza y ver al pueblo agolpado para presenciar su sacrificio, exclamo: '¡Pueblo indolente! ¡Cuán diversa sería hoy vuestra suerte si conocieseis el precio de la libertad! Pero no es tarde. Ved que aunque mujer y joven, me sobra valor para sufrir la muerte y mil muertes más, y no olvidéis este ejemplo...' Mayor era el esfuerzo de los sacerdotes en no dejar que estas exhortaciones patrióticas de la Pola fuesen oídas por la multitud, y a la verdad, que no podían ser distinguidas y recogidas sino por los que iban tan inmediatos a ella como yo. Llegada al pie del banquillo volvió otra vez los ojos al pueblo y dijo: ' $¡ M$ Miserable pueblo! Yo os compadezco; algún día tendréis más dignidad.' Entonces se le ordenó que se montase sobre la tableta del banquillo porque debía ser fusilada por la espalda como traidora; ella contestó: 'Ni es propio ni decente de una mujer semejante posición; pero sin montarme, yo daré la espalda si esto es lo que se quiere.' Medio arrodillándose luego sobre el banquillo y presentando la mayor parte de la espalda, se la vendó y aseguró con cuerdas, en cuya actitud recibieron, ella y sus compañeros, una muerte que ha eternizado los nombres y hecho multiplicar los frutos de la libertad." J. M. Restrepo \& E. Ortega, La Pola yace para salvar la patria, Bogotá, Ministerio de Educación Nacional, 1949, p. 46.
} 
uma das mulheres participantes nas Juntas, que posteriormente vai apoiar os patriotas de Cundinamarca com armas, dinheiro e roupas. Durante a Pacificação, acaba exilada. Policarpa e Rodríguez de Gaitán, em menor medida, terão o maior número de representações iconográficas durante o século XIX.

A lista de mulheres mártires e heroínas da Independência é longa, embora não seja assim sua representação pictórica. Essa marginalidade das mulheres nas representações visuais também pode ser vista na História escrita, que destacava mais os homens e os grandes eventos. As poucas mulheres representadas pictoricamente são mais vistas pelas suas relações como esposas, mães, e dificilmente são reconhecidas por seu papel político. Outras mulheres sem nome seriam representadas como alegorias da Pátria, da República e da Liberdade.

Só Policarpa Salavarrieta consegue ser representada como sujeito político, que na sua maioria é masculino, não permitindo espaço à mulher. A mulher transformou-se em imagem alegórica da liberdade, mas não em um sujeito político ativo e transcendental dentro da revolução. ${ }^{40}$

Policarpa, em sua representação iconográfica, é um sujeito autônomo que luta pela liberdade, ao ponto que sua relação com Sabaraín desaparece nas imagens, sendo ela apresentada sozinha, disposta e altiva perante o martírio, acabando associada à Virgem na sua representação. Segundo Agulhon, ${ }^{41}$ duas imagens femininas foram usadas durante a Revolução Francesa como alegorias da República: por um lado, Maria, a Virgem, e, pelo outro, Marianne, uma mulher do povo. No caso colombiano, a iconografia de La Pola estará mais associada a Maria que a Marianne.

Tanto Maurice Agulhon quanto José Murilo de Carvalho destacam a falta de reconhecimento da mulher como sujeito político ativo, nos casos da França e do Brasil, e poderíamos somar aqui também o caso colombiano. Então, o uso simbólico da imagem feminina como heroína pode ser pensado como uma compensação à marginalização real da mulher, à sua ausência como sujeito político. Mas as imagens também são um reconhecimento limitado da sua vital participação na Independência, evidenciando, assim, que o conjunto da sociedade participou do processo de construção nacional.

\footnotetext{
${ }^{40}$ Ver o capítulo 4. "República-mujer: entre María y Marianne”, Carvalho, op. cit., p. 113-155.

${ }^{41}$ Ver Maurice Agulhon, Marianne au combat. L'imagerie et la symbolique républicaines de 1789 à 1880, París, Flammarion, 1979.
} 
As pinturas de heróis e heroínas, além de darem legitimidade à República, foram a resposta à necessidade de construir uma memória da Independência e de produzir símbolos para o novo regime, além de ensinar um conjunto de valores sociais e políticos. Sacrifício, devoção, honra, justiça, valor e amor à pátria são alguns dos valores que os artistas deviam difundir por meio das suas obras.

A análise das representações pictóricas, como as alegorias da pátria e os retratos de heróis, é fonte fundamental no estudo da cultura e das linguagens políticas, já que amplia o horizonte discursivo e apresenta diferentes pontos de vista quanto ao processo de construção de novos símbolos de poder e modelos exemplares para legitimar a nascente República, e posteriormente os governos, os partidos, os notáveis, ensinando virtudes como a cidadania, a liberdade, a igualdade e o respeito pela Constituição. 